\title{
Trends in antimony pollution near exposed traffic nodes: comparison with arsenic
}

\author{
B. Dousova ${ }^{1}$, M. Lhotka ${ }^{1}$, V. Machovic ${ }^{1}$, F. Buzek ${ }^{2}$, B. Cejkova ${ }^{2}$ \& I. Jackova ${ }^{2}$ \\ ${ }^{1}$ University of Chemistry and Technology Prague, Prague, Czech Republic \\ ${ }^{2}$ Czech Geological Survey, Prague, Czech Republic
}

\begin{abstract}
The significant part of antimony $(\mathrm{Sb})$ contamination can be associated with extremely loaded traffic areas, where braking vehicles produce the abrasion dust containing up to $5 \%$ wt. of $\mathrm{Sb}_{2} \mathrm{~S}_{3}$. Heavy loaded cross-roads from three different regions of the Czech Republic (Central Europe) were monitored for Sb content in road dusts, topsoils and reference soils during the two-year season (2015-2017). The concentration of antimony exceeded up to 60 times the background values and varied from 5 to $70 \mu \mathrm{gg}^{-1}$ in topsoils, and from 70 to $160 \mu \mathrm{g} \mathrm{g}^{-1}$ in road dusts with the preferable binding to fine particle fraction $(<0.1 \mathrm{~mm})$.
\end{abstract}

\section{INTRODUCTION}

Antimony $(\mathrm{Sb})$ is a global environmental contaminant and one of the elements of increasing environmental significance. While arsenic (As) represents a historical toxic substance monitored in the long term, antimony is a typical emerging contaminant that has been classified as a serious problem for future generations (CEC, 1998). The significant part of $\mathrm{Sb}$ contamination can be associated with extremely loaded traffic areas, where braking vehicles produce the abrasion dust containing up to $5 \%$ wt. of $\mathrm{Sb}_{2} \mathrm{~S}_{3}$. Antimony released during braking process is mostly bound in fine atmospheric particulate matter, i.e. in $\mathrm{PM}_{10}$ (ca $32 \mu \mathrm{g} \mathrm{Sb} / \mathrm{braking} /$ car) and $\mathrm{PM}_{2.5}$ (ca $22 \mu \mathrm{g} \mathrm{Sb} /$ braking/car) (Iijima et al., 2008), a minor part remains in non-exhaust traffic emmissions (road dust). Roadside topsoils accumulate large amounts of vehicle emissions, so the concentrations of antimony in them can reach more than 60 times of background value. As with arsenic, the soil $\mathrm{pH} / \mathrm{Eh}$ importantly determine antimony species in soils. Arsenic has been found as pentavalent arsenate, $\mathrm{AsO}_{4}^{3-}$ in the oxidic surface zone $(0-3 \mathrm{~cm})$ and as trivalent arsenite, $\mathrm{AsO}_{3}^{3-}$ under slightly reducing conditions $(9-12 \mathrm{~cm})$ (Wilson et al., 2010), while antimony as pentavalent hydrated antimonate, $\mathrm{Sb}(\mathrm{OH})_{6}^{-}$ represents the major oxidation state over a wide Eh range (Mitsunobu et al., 2008).

The binding of both As and $\mathrm{Sb}$ oxyanions in soils has been mostly controlled by the complexation with iron $\left(\mathrm{Fe}^{\mathrm{III}}\right)$, whereas $\mathrm{Sb}$ exhibits significantly higher affinity to natural organic matter (NOM) compare to As (Mitsunobu et al., 2008).

The aim of this study was to monitore heavy loaded cross-roads from three different regions of the Czech Republic (Central, South and East Bohemia) for antimony content in road dusts and topsoils during the two-year season (2015-2017). The same samples were tested for As content to the evaluation of current contamination trends in exposed urban areas.

\section{EXPERIMENTAL}

\subsection{Sampling}

Road dusts and urban topsoils $(0-5 \mathrm{~cm})$ were collected periodically (4 sampling data during 2015-2017) at busy cross-roads in three big cities in the Czech Republic (Prague (P) in middle Bohemia, České Budějovice $(\mathrm{CB})$ in southern Bohemia and industrial Ostrava (O) in eastern Bohemia) and kept in PVC packages. Topsoils were taken as three sub-samples from the area of $20 \times 20 \mathrm{~cm}$, mixed together, quartered, dried and sieved to $<0.315-0.1 \mathrm{~mm}$ and $<0.1 \mathrm{~mm}$ fractions, respectively. Road dusts were collected close to roads exposed to heavy traffic circulation, mixed together, dried and sieved to $<0.315-0.1 \mathrm{~mm}$ and $<0.1 \mathrm{~mm}$ fractions, respectively.

\subsection{Sample processing}

The fractions of solid samples were analysed for major components by XRF (Rigaku NEX QC), for the specific surface area as $S_{\text {BET }}$ (Micromeritics ASAP 2020) and for TOC using elementary analysis (Fisons 1108). Finally, all samples were mineralized by microwave digestion (Berghof MWS-2 speedwave) with $\mathrm{HCl}$ and $\mathrm{HNO}_{3}(1: 3)$.

The concentration of $\mathrm{Sb}$ in aqueous solutions was determined by HG-AFS using PSA 10.055 Millennium Excalibur. The samples were pre-treated with a solution of $\mathrm{HCl}(36 \% \mathrm{v} / \mathrm{w})$ and $\mathrm{KI}(50 \%)$ with ascorbic acid (10\%). The declared detection limit was $0.05 \mathrm{ppm}$ 
Table 1. Average Sb concentration $\left(\mu \mathrm{g} \mathrm{g}^{-1}\right)$ in topsoil and road dust fractions.

\begin{tabular}{|c|c|c|c|c|}
\hline \multirow[b]{2}{*}{ Locality } & \multicolumn{2}{|c|}{ Urban soils } & \multicolumn{2}{|c|}{ Road dust } \\
\hline & $<0.1^{*)}$ & $0.1-0.315$ & $<0.1$ & $0.1-0.315$ \\
\hline $\mathrm{P}$ & 13.6 & 5.5 & 45.3 & 29.9 \\
\hline $\mathrm{CB}$ & 53.7 & 23.1 & 164.6 & 89.1 \\
\hline $\mathrm{O}$ & 5.6 & 2.5 & 12.8 & 6.5 \\
\hline
\end{tabular}

*) particle size in $\mathrm{mm}$

and the standard deviation was experimentally determined as $2.5 \%$.

\section{RESULTS AND DISCUSSION}

\subsection{Antimony content in topsoils and road dust}

The data in Table 1 illustrate a major binding of $\mathrm{Sb}$ in fine particles (more than double the concentrations compare to the coarser fraction), and a significantly higher content of $\mathrm{Sb}$ in road dust compare to soils. While the concentration ranged from units to tens of $\mu \mathrm{g} \mathrm{g}^{-1}$, in road dust it reached up to tens to hundreds of $\mu \mathrm{g} \mathrm{g}^{-1}$ in topsoils. Evident local variability in $\mathrm{Sb}$ contamination $(\mathrm{CB}>>\mathrm{P}>\mathrm{O}$ ) can be explained by the different traffic intensity at the sampling sites.

\subsection{Antimony correlation with $\mathrm{Fe}$ and $\mathrm{OM}$}

In all aspects, antimony demonstrated better correlation with organic matter than with Fe. Very good $\mathrm{Sb} / \mathrm{C}_{\text {org }}$ correlation $\left(\mathrm{R}^{2}=0.893\right)$ was found in topsoils, less apparent correlation factor $\left(\mathrm{R}^{2}=0.702\right)$ could be assigned to $\mathrm{Sb} / \mathrm{C}_{\text {org }}$ in road dust. Unlike arsenic, that exhibited high positive correlation with $\mathrm{Fe}$ in different natural solids (Dousova et al., 2012), Sb/Fe correlation in topsoils was worse $\left(\mathrm{R}^{2}=0.594\right)$ and even none $\mathrm{Sb} / \mathrm{Fe}$ correlation was found in road dust.

\subsection{Important trends in $\mathrm{Sb}$ and As pollution in urban areas}

The contamination impact of brake abrasion (Fig. 1) illustrated decreasing trend in $\mathrm{Sb}$ content from source brake abrasion over the road dust and topsoils to the reference soils, which were collected in places without transport, as close as possible to the sampling sites. Nevertheless, the minimum Sb concentration measured in the reference soils exceeded the declared background value $\left(0.1-1.9 \mu \mathrm{g} \mathrm{g}^{-1}\right)$ markedly.

Thanks to brake pads abrasion and growing usage of PET bottles the world antimony production sharply increased over the last 40 years (USGS, 2017). Conversely, in most of European countries arsenic emissions declined by $70-85 \%$ following the considerable decrease of atmospheric emissions in Central Europe from 1985-2000. Over the 20-year time span As concentrations in vertical atmospheric deposition decreased 8 times, those in interception deposition decreased 16 times (Doušová et al., 2007).

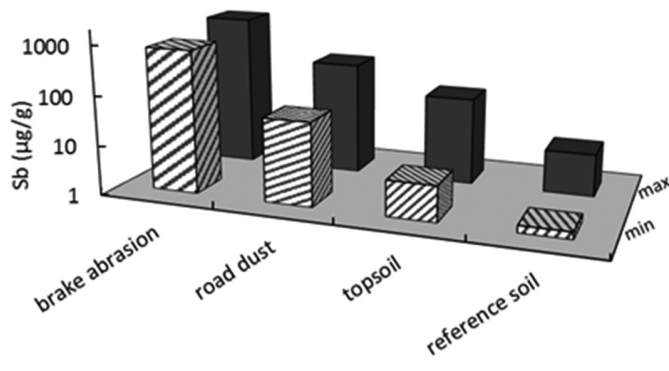

Figure 1. Contamination effect of source brake abrasion.

\section{CONCLUSIONS}

Brake abrasion dust represents one of the major sources of antimony pollution. In exposed localities antimony concentration exceeded up to 60 times the background value and decreased in the order: brake abrasion $\left(\approx 10^{3} \mu \mathrm{gg}^{-1}\right)>$ road dust $\left(\approx 10^{2} \mu \mathrm{g} \mathrm{g}^{-1}\right)>$ topspoils $\left(\approx 10^{1} \mu \mathrm{g} \mathrm{g}^{-1}\right) \gg$ reference soils $\left(<1 \mu \mathrm{gg}^{-1}\right)$ being mostly accumulated in fine particles. Contrary to arsenic, antimony correlated better with $\mathrm{OM}$ than with $\mathrm{Fe}$ in topsoils, its straight correlation with $\mathrm{Fe} / \mathrm{OM}$ in road dust was not observed. While arsenic contamination has recently decreased thanks to a massive decline of arsenic emissions, antimony contamination indicates a dangerous progress due to growing automotive traffic.

\section{ACKNOWLEDGEMENTS}

This work was part of projects 16-13778S (Grant Agency of Czech Republic).

\section{REFERENCES}

CEC, 1998. Evaluating the cost and supply of alternatives to MTB in Californias's reformulated gasoline. Draft Report. California Energy Commission.

Doušová, B., Erbanová, L., \& Novák, M. 2007. Arsenic in artmospheric deposition at the Czech-Polish border: Two sampling campaigns 20 years apart. Sci. Total Environ. 387: 185-193.

Dousova, B., Buzek, F., Rothwell, J., Krejcova, S. \& Lhotka, M. 2012. Adsorption behavior of arsenic relating to different natural solids: soils, stream sediments and peats. Sci. Total Environ. 433: 456-461.

Iijima, A., Sato, K., Yano, K., Kato, M., Kozawa, K. \& Furuta, N. 2008. Emission factor for antimony in brake abrasion dusts as one of the major atmospheric antimony sources. Environ. Sci. Technol. 42: 2937-2942.

Mitsunobu, S., Takahashi, Y. \& Sakai, Y. 2008. Abiotic reduction of antimony(v) by green rust $\left(\mathrm{Fe}_{4}(\mathrm{II}) \mathrm{Fe}_{2}(\mathrm{III})(\mathrm{OH})_{12}\right.$ $\left.\mathrm{SO}_{4} .3 \mathrm{H}_{2} \mathrm{O}\right)$. Chemosphere. 70: 942-947.

USGS. 2017. Mineral commodity summaries 2017: United States Geological Survey 202p. (https://doi.org/10.3133/ 70180197).

Wilson, S.C., Lockwood, P.V., Ashley, P.M. \& Tighe, M. 2010. The chemistry and behaviour of antimony in the soil environment with comparisons to arsenic: a critical review. Environ. Pollut., 158: 1169-1181. 